\title{
In matters of the heart, do not neglect the lungs: Influence of chronic obstructive pulmonary disease severity on outcomes after off-pump coronary artery bypass graft procedure
}

\author{
Shuab Omer, MD \\ From the Division of Cardiothoracic Surgery, The Baylor College of Medicine/Michael E DeBakey VA Medical \\ Center, Houston, Tex. \\ Disclosures: Author has nothing to disclose with regard to commercial support. \\ Received for publication April 30, 2018; revisions received April 30, 2018; accepted for publication May 2, 2018; \\ available ahead of print June 20, 2018. \\ Address for reprints: Shuab Omer, MD, Division of Cardiothoracic Surgery, Baylor College of Medicine/Michael \\ E DeBakey VA Medical Center, 2002 Holcombe Blvd, Houston, TX 77030 (E-mail: shuab.omer@bcm.edu). \\ J Thorac Cardiovasc Surg 2018;156:1562-3 \\ 0022-5223/\$0.00 \\ Published by Elsevier Inc. on behalf of The American Association for Thoracic Surgery \\ https://doi.org/10.1016/j.jtcvs.2018.05.016
}

Chronic obstructive pulmonary disease (COPD) is projected to be the third leading cause of death by $2020{ }^{1}$ COPD frequently coexists with comorbidities that significantly influence its prognosis. ${ }^{2}$ Because COPD and coronary artery disease have common risk factors, a high percentage of patients undergoing coronary artery bypass grafting $(\mathrm{CABG})$ procedures have underlying COPD.

Multiple studies have demonstrated the adverse influence of COPD on mortality and morbidity after CABG. ${ }^{3-6}$ However, in these studies, the severity of COPD was not consistently defined, and the investigators frequently relied on arbitrary clinical labels of COPD. The universal acceptance of the Global Initiative for Chronic Obstructive Lung Disease (GOLD) criteria $^{2}$ has addressed this lack of uniformity in COPD diagnosis. The GOLD criteria categorize symptomatic COPD on the basis of spirometric findings in patients with forced expiratory volume in 1 second $\left(\mathrm{FEV}_{1}\right) /$ forced vital capacity $<70 \%$ : mild COPD is determined at $\mathrm{FEV}_{1} \geq 80 \%$, moderate COPD is determined at $\mathrm{FEV}_{1}<80 \%$, severe COPD is determined at $\mathrm{FEV}_{1}<50 \%$, and very severe COPD is determined at $\mathrm{FEV}_{1} \leq 30 \%$.

Viceconte and colleagues ${ }^{7}$ studied the influence of COPD severity, based on the GOLD criteria, on pulmonary function and outcomes after off-pump CABG. In this prospective cohort study, the authors reported that severe COPD was associated with worse clinical outcomes in examining the rates of pneumonia, reintubation, prolonged mechanical ventilation, and increased length of stay. ${ }^{7}$ Postoperative pulmonary dysfunction was significantly higher in moderate and severe COPD groups, and a preoperative $\mathrm{FEV}_{1}<50 \%$ was an important predictor of complications. Their results are consistent with those of other studies that were not based on the GOLD criteria. ${ }^{3-6}$

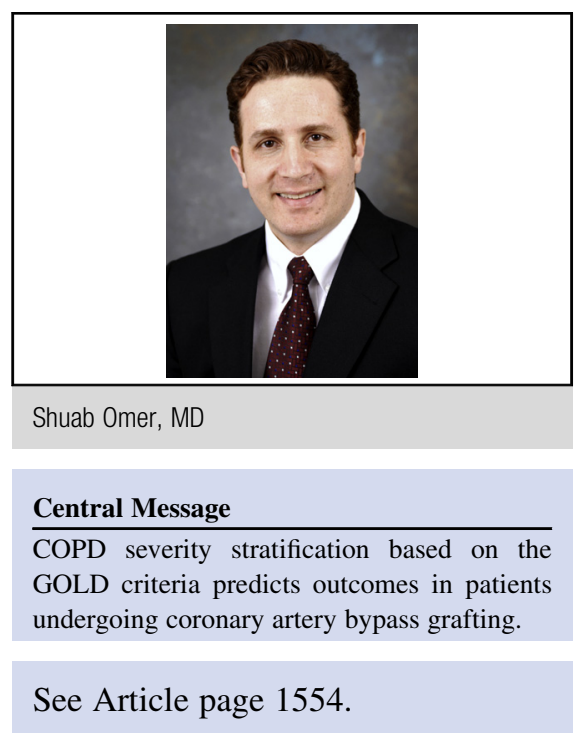

Using the standardized spirometric GOLD criteria routinely to assess COPD severity before CABG to predict outcomes is a compelling approach. ${ }^{2}$ However, symptom severity, regardless of spirometry results, may also play an important role. Thus, complementary tools, such as the COPD assessment test, ${ }^{8}$ the ABCD grading system, and the Body-Mass Index, Airflow Obstruction, Dyspnea, and Exercise Capacity Index ${ }^{9}$ may also be included in the risk assessment because they may help predict COPD exacerbations, acute deterioration of health status, and mortality per the latest GOLD guidelines. ${ }^{2}$

COPD is strongly associated with other comorbidities, such as heart failure, arrhythmias, peripheral vascular disease, hypertension, osteoporosis, depression, lung cancer, metabolic syndrome, gastroesophageal reflux disease, bronchiectasis, and obstructive sleep apnea. These comorbidities can individually and in concert influence outcomes in patients with COPD. Leavitt and colleagues ${ }^{4}$ reported that the 10 -year survival rate was just $30 \%$ after CABG in patients with COPD who had only 1 other additional comorbidity. In the study by Viceconte and colleagues, ${ }^{7}$ propensity matching for comorbidities was not performed; therefore, the results may not truly reflect the influence of COPD alone.

The approach to severity staging for COPD is evolving, and future studies will undoubtedly identify new COPD 
classification systems for patients undergoing cardiac surgery. The GOLD criteria appear to be robust in predicting outcomes after CABG; however, their use needs to be validated in larger studies of patients undergoing cardiac surgery before the criteria can eventually be incorporated into the Society of Thoracic Surgeons predicted risk of mortality score.

\section{References}

1. Rabe KF, Hurd S, Anzueto A, Barnes PJ, Buist SA, Calverley P, et al. Global strategy for the diagnosis, management, and prevention of chronic obstructive pulmonary disease: GOLD executive summary. Am J Respir Crit Care Med. 2007;176: 532-55.

2. Vogelmeier CF, Criner GJ, Martinez FJ, Anzueto A, Barnes PJ, Bourbeau J, et al. Global strategy for the diagnosis, management, and prevention of chronic obstructive lung disease 2017 report: GOLD executive summary. Eur Respir J. 2017;49.

3. Angouras DC, Anagnostopoulos CE, Chamogeorgakis TP, Rokkas CK, Swistel DG, Connery CP, et al. Postoperative and long-term outcome of patients with chronic obstructive pulmonary disease undergoing coronary artery bypass grafting. Ann Thorac Surg. 2010;89:1112-8.

4. Leavitt BJ, Ross CS, Spence B, Surgenor SD, Olmstead EM, Clough RA, et al Long-term survival of patients with chronic obstructive pulmonary disease undergoing coronary artery bypass surgery. Circulation. 2006;114:I430-4.

5. Medalion B, Katz MG, Cohen AJ, Hauptman E, Sasson L, Schachner A. Long term beneficial effect of coronary artery bypass grafting in patients with COPD Chest. 2004;125:56-62.

6. Nishiyama K, Morimoto T, Furukawa Y, Nakagawa Y, Ehara N, Taniguchi R, et al Chronic obstructive pulmonary disease-an independent risk factor for long-term cardiac and cardiovascular mortality in patients with ischemic heart disease. Int J Cardiol. 2010;143:178-83.

7. Viceconte M, Rocco IS, Pauletti HO, Vidotto M, Arena R, Gomes WJ, et al Chronic obstructive pulmonary disease severity influences outcomes after off-pump coronary artery bypass. J Thorac Cardiovasc Surg. 2018;156:1554-61.

8. Jones PW, Harding G, Berry P, Wiklund I, Chen WH, Kline Leidy N. Development and first validation of the COPD Assessment Test. Eur Respir J. 2009;34:648-54.

9. Celli BR, Cote CG, Marin JM, Casanova C, Montes de Oca M, Mendez RA, et al The body-mass index, airflow obstruction, dyspnea, and exercise capacity index in chronic obstructive pulmonary disease. N Engl J Med. 2004;350:1005-12. 